\title{
SISTEM PENDUKUNG KEPUTUSAN DALAM PEMILIHAN PENGEMBANGAN MODEL PEMBELAJARAN DENGAN METODE AHP
}

\author{
Zulfi Azhar*1, Wakhinuddin $^{2}$, Waskito ${ }^{2}$ \\ ${ }^{1}$ Sistem Informasi, STMIK Royal Kisaran \\ ${ }^{2}$ Fakultas Teknik, Universitas Negeri Padang \\ email: "zulfi_azhar@yahoo.co.id
}

\begin{abstract}
Education as an important aspect, in improving the quality of education needs to be done innovatively. Learning Models are examples of student learning patterns or structures that are designed, implemented, and systematically evaluated by teachers in order to achieve learning objectives. The Industrial Revolution 4.0 currently has an influence in various fields, one of which is the world of education, with IoT presenting an industrial revolution in the world of education in finding ways to implement learning systems so that they are not outdated. STMIK Royal is one of the computer high schools in Kisaran that wants to develop a better learning model for its students. In choosing the development of learning models requires a decision support system method in choosing the best using the AHP method. This method can analyze a number of criteria and alternatives in choosing the best learning model development which is determined through the calculation process. This model is easier and more effective to produce the best. The AHP method is able to produce the selection of learning model development with several selection criteria and influential alternative choices. The result of the highest ranking is a priority on criteria and alternatives in achieving the goal of choosing a learning model at STMIK Royal Kisaran.
\end{abstract}

Keywords: alternative; analytical hierarchy process; criteria, development; learning models

\begin{abstract}
Abstrak: Pendidikan sebagai aspek penting, dalam peningkatan mutu pendidikan perlu dilakukan secara inovatif. Model Pembelajaran adalah contoh pola atau struktur belajar siswa yang dirancang, dilaksanakan, dan dievaluasi secara sistematis oleh guru dalam rangka mencapai tujuan pembelajaran. Revolusi Industri 4.0 saat ini telah memberikan pengaruh di berbagai bidang salah satunya dunia pendidikan, dengan IoT menghadirkan revolusi industri di dunia pendidikan dalam mencari jalan mengimplementasikan sistem pembelajaran agar tidak ketinggalan zaman. STMIK Royal merupakan salah satu sekolah tinggi komputer di Kisaran yang ingin mengembangkan model pembelajaran yang lebih baik bagi mahasiswanya. Dalam memilih pengembangan model pembelajaran memerlukan metode sistem pendukung keputusan dalam memilih yang terbaik menggunakan metode AHP. Metode ini dapat menganalisis sejumlah kriteria dan alternatif dalam memilih pengembangan model pembelajaran terbaik yang ditentukan melalui proses perhitungan. Model ini lebih mudah dan efektif untuk menghasilkan yang terbaik. Metode AHP mampu menghasilkan pemilihan pengembangan model pembelajaran dengan beberapa kriteria seleksi dan alternatif pilihan yang berpengaruh. Hasil perangkingan tertinggi merupakan prioritas pada kriteria dan alternatif dalam pencapaian tujuan memilih model pembelajaran di STMIK Royal Kisaran.
\end{abstract}

Kata kunci: alternatif; analytical hierarchy process; kriteria; pengembangan; model pembelajaran 
DOI: https://doi.org/10.33330/jurteksi.v7i3.1155

Available online at http://jurnal.stmikroyal.ac.id/index.php/jurteksi

\section{PENDAHULUAN}

Pendidikan merupakan salah satu aspek yang sangat penting dalam kehidupan manusia. Upaya peningkatan mutu pendidikan terus dilakukan secara inovatif. Pendidikan diharapkan dapat meningkatkan kreativitas dalam memecahkan suatu masalah. Kreativitas diperlukan untuk menghadapi perubahan global dan persaingan pasar bebas, serta tuntutan kemajuan ilmu pengetahuan dan teknologi[1]. Kreativitas juga merupakan komponen penting dalam pembelajaran kontekstual agar berhasil dalam menghadapi dunia yang kompleks menyatakan bahwa pengembangan kreativitas tidak hanya memperhatikan pengembangan kemampuan berpikir kreatif, tetapi juga penanaman sikap dan sifat kepribadian kreatif. Kreativitas dapat menggambarkan cara berpikir yang lebih adaptif dan dapat ditumbuhkan dan dikembangkan melalui proses pemecahan masalah dan memiliki pemahaman yang tinggi[2].

Selama ini kreativitas peserta didik belum banyak dikembangkan di sekolah, padahal untuk menyelesaikan permasalahan yang semakin kompleks diperlukan kreativitas yang tinggi agar dapat memilih solusi yang tepat. Sebagian besar siswa kurang mampu menyesuaikan diri dengan perubahan maupun perkembangan ilmu pengetahuan dan teknologi, sulit untuk bisa memotivasi diri, dan kurang bisa mengembangkan kreativitas yang ada pada diri masingmasing siswa. Berdasarkan permasalahan tersebut perlu diupayakan model pembelajaran yang dapat memandu siswa dalam belajar berorientasi pada pengetahuan yang dimiliki siswa, salah satunya dengan menggunakan model pembelajaran yang relevan[2].

Model pembelajaran adalah contoh pola atau struktur belajar siswa yang dirancang, dilaksanakan, dan dievaluasi secara sistematis oleh guru dalam rangka mencapai tujuan pembelajaran. Dalam pengertian lain, model pembelajaran merupakan contoh bentuk pembelajaran yang digambarkan dari awal sampai akhir pembelajaran yang disajikan secara khas oleh guru di kelas[3].

Pendekatan pembelajaran yang sifatnya masih sangat umum, yang di dalamnya mengakomodir, mengilhami, memperkuat, dan melandasi metode pembelajaran dengan cakupan teoritis tertentu. Strategi pembelajaran dilaksanakan agar tujuan pembelajaran dapat tercapai secara efektif dan efisien. Metode pembelajaran sebagai implementasi rencana yang telah disusun dalam bentuk kegiatan nyata dan praktis untuk mencapai tujuan pembelajaran. Teknik pembelajaran menerapkan suatu metode tertentu, taktik belajar merupakan gaya seorang pengajar dalam menerapkan metode belajar individu tertentu.

Revolusi Industri 4.0 saat ini telah memberikan pengaruh di berbagai bidang salah satunya dunia pendidikan, dengan IoT menghadirkan revolusi industri di dunia pendidikan dalam mencari jalan mengimplementasikan sistem pembelajaran agar tidak ketinggalan zaman. STMIK Royal merupakan salah satu sekolah tinggi komputer di Kisaran yang ingin mengembangkan model pembelajaran yang lebih baik bagi mahasiswanya. Dalam memilih pengembangan model pembelajaran memerlukan metode sistem pendukung keputusan dalam memilih yang terbaik menggunakan metode AHP.

Pemilihan pengembangan model pembelajaran menggunakan beberapa kriteria dan alternatif dengan metode Analytical Hierarchy Process (AHP).. 
Dalam metode ini diperlukan beberapa kriteria dan beberapa alternatif sebagai pilihan yang ditentukan melalui proses perhitungan. Cara ini lebih mudah dan efektif untuk menghasilkan yang terbaik. menjadikan bagian-bagian hierarki dan bertahap [4]-[13].

Model pembelajaran yaitu bentuk pembelajaran dari awal sampai akhir yang disajikan oleh guru yang merupakan kerangka penerapan suatu metode, pendekatan dan teknik pembelajaran yang mampu mengembangkan kemampuan siswa dalam berbagai tujuan pembelajaran[14], pengembangan model banyak variasi, kreatif, keberhasilan kemampuan siswa pada pembelajaran tematik[15].

Model pembelajaran tidak ada yang cocok untuk semua situasi dan kondisi, ada memiliki beberapa kelebihan dan keterbatasan[16], mampu membantu mengembangkan dalam ranah kognitif, intelektual peserta didiknya[17], memerlukan inovasi dalam proses belajar mengajar yang kondusif demi tercapai tujuan pembelajaran[18]. disesuaikan dengan karakteristik siswa, tujuan, bahan ajar, alat/media, waktu yang tersedia, situasi dan kondisi[19].

Metode pembelajaran adalah metode yang digunakan untuk melaksanakan rencana yang telah disusun dalam bentuk kegiatan nyata dan praktis untuk mencapai tujuan pembelajaran. Metode ini dapat digunakan untuk menerapkan strategi pembelajaran dengan ceramah, demonstrasi, diskusi, simulasi, laboratorium, debat, dan lain-lain. Kemampuan pendidik menjadi salah satu pertimbangan dalam memilih sebuah pembelajaran. Dosen yang tidak memahami penggunaan metode pembelajaran tidak akan mampu melaksanakan proses pembelajaran.

Kemampuan mahasiswa perlu diperhatikan seberapa intelektual mahasiswanya agar dapat menggunakan metode yang tepat. Banyaknya mahasiswa menentukan dalam metode pembelajaran, jenis materi yang disampaikan oleh dosen sangat penting untuk diperhatikan secara khusus. Waktu juga dapat mempengaruhi dosen dalam menentukan model pembelajaran disamping banyak kegiatan lainnya. Fasilitas juga mempengaruhi penentuan dengan metode observasi/praktek.

Sistem Pendukung Keputusan (SPK) merupakan sistem pengolah data dalam mengambil keputusan[20]. Sistem Pendukung Keputusan merupakan alat interaktif dalam mengambil keputusan dengan berbagai analisis[21], memberikan informasi, pemodelan, dan manipulasi data, menganalisis menggunakan metode yang tersedia[22].

AHP menggunakan perbandingan pasangan juga mengandalkan penilaian dalam menghasilkan skala prioritas[23][26]. AHP sederhana, fleksibel, akurat dan mudah dipahami, prosesnya mengandalkan penalaran matematis dan logis untuk sampai pada pengambilan keputusan[27], sebagai metode pemecahan masalah dengan metode lain dengan beberapa alasan[28].

\section{METODE}

Metode pada penelitian ini menggunakan beberapa tahap yaitu:

\section{Tahap 1 Mengumpulkan Dokumen Data}

Pengumpulan data dilakukan di lapangan dengan memilih sejumlah kriteria dan alternatif menggunakan pengisian formulir oleh 50 orang dosen sebagai responden di STMIK Royal. Mereka diminta untuk membandingkan kriteria 
yang dibutuhkan dan data tersebut akan diolah untuk dianalisis.

\section{Tahap 2 Menganalisa Data.}

Menganalisa data dengan sejumlah kriteria dan alternatif yang dipilih sesuai tujuanl yang direncanakan.

\section{Tahap 3 Menggunakan proses uji} pada Sistem.

Penggunaan matriks excel, pada pengujian perhitungan pada sistem. Beberapa langkah pada metode AHP : a). Pendefinisian masalah; b). Penentuan elemen prioritas; c). Sintesis dan d). Mengukur konsisten [29].

Menghitung Consistency Index (CI)

$$
\mathrm{CI}=\frac{[\lambda \max -n]}{\mathrm{n}-1}
$$

dimana :

$$
\begin{aligned}
& \mathrm{n}=\text { banyak elemen } \\
& \lambda \text { maks = angka eigen } \\
& \mathrm{CI}=\text { Index of Consistency, }
\end{aligned}
$$

Perhitungan untuk Ratio of Consistency (CR)

$$
C R=\frac{C I}{R I}
$$

Pemeriksaan Konsistensi Hirarki dinyatakan benar dan konsistensi,

$$
\mathrm{CR}<0,10
$$

\section{HASIL DAN PEMBAHASAN}

\section{Penilaian Untuk Kriteria}

Kriteria yang mempengaruhi pemilihan pengembangan model pembelajaran adalah: Tujuan Pembelajaran (Crt1), Kemampuan Dosen (Crt2), Kemampuan Mahasiswa (Crt3), Jumlah Mahasiswa (Crt4) Jenis Materi (Crt5), Waktu (Crt6) dan Fasilitas yang Tersedia (Crt7).

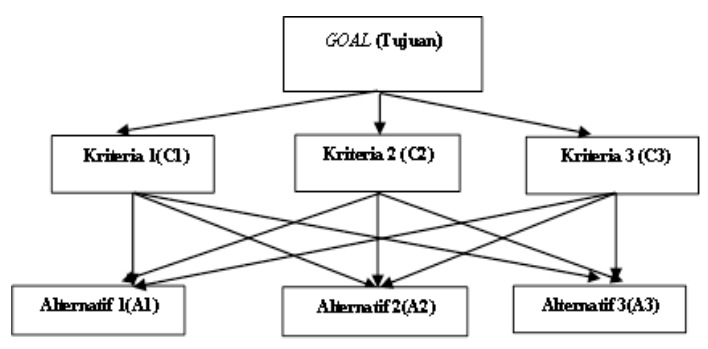

Gambar 1. Struktur Hirarki dalam Metode AHP

dimana : $\mathrm{CR}=$ Ratio of Consistency, $\mathrm{RI}=$ Index of Random

Tabel 1. Penilaian Secara Hirarki

\begin{tabular}{ccl}
\hline Nilai & \multicolumn{1}{c}{ Artinya } & \multicolumn{1}{c}{ Keterangan } \\
\hline Angka 1 & Sama -sama penting & Punya pengaruh sama \\
Angka 3 & Sedikit penting & Berbanding sedang terhadap lainnya \\
Angka 5 & Lebih penting & Berbanding lebih terhadap lainnya \\
Angka 7 & Sangat penting & Berbanding sangat lebih dengan lainnya \\
Angka 9 & Mutlak penting & Berbanding lebih kuat dengan lainnya \\
Angka 2, 4.6.8 & Nilai diantaranya & Nilai saling berdekatan
\end{tabular}

Tabel 2. Perhitungan Untuk Kriteria

\begin{tabular}{cccccccc}
\hline Kriteria $(\mathrm{Crt})$ & Crt1 & Crt2 & Crt3 & Crt4 & Crt5 & Crt6 & Crt7 \\
\hline Crt 1(C1) & 1 & 5 & 5 & 3 & 3 & 5 & 5 \\
\hline Crt 2(C2) & 0,2 & 1 & 5 & 5 & 3 & 3 & 3 \\
\hline Crt 3(C3) & 0,2 & 0,2 & 1 & 5 & 5 & 5 & 5 \\
Crt 4(C4) & 0,333 & 0,2 & 0,2 & 1 & 5 & 3 & 3 \\
Crt 5(C5) & 0,333 & 0,333 & 0,2 & 0,2 & 1 & 5 & 3 \\
Crt 6(C6) & 0,2 & 0,333 & 0,2 & 0,333 & 0,2 & 1 & 3 \\
\hline Crt 7(C7) & 0,2 & 0,333 & 0,2 & 0,333 & 0,333 & 0,333 & 1 \\
\hline Jumlah & 2,467 & 7,4 & 11,8 & 14,867 & 17,533 & 22,333 & 23 \\
\hline
\end{tabular}


DOI: https://doi.org/10.33330/jurteksi.v7i3.1155

Available online at http://jurnal.stmikroyal.ac.id/index.php/jurteksi

Tabel 3. Normalisasi Pada Kriteria

\begin{tabular}{ccccccccc}
\hline $\begin{array}{c}\text { Kriteria } \\
(\text { Crt })\end{array}$ & Crt1 & Crt2 & Crt3 & Crt4 & Crt5 & Crt6 & Crt7 & Jumlah \\
\hline Crt 1 & 0,405 & 0,676 & 0,424 & 0,202 & 0,171 & 0,224 & 0,217 & 2,319 \\
Crt 2 & 0,081 & 0,135 & 0,424 & 0,336 & 0,171 & 0,130 & 0,130 & 1,412 \\
Crt 3 & 0,081 & 0,027 & 0,085 & 0,336 & 0,285 & 0,217 & 0,217 & 1,256 \\
Crt 4 & 0,135 & 0,027 & 0,017 & 0,067 & 0,285 & 0,130 & 0,130 & 0,796 \\
Crt 5 & 0,135 & 0,045 & 0,017 & 0,013 & 0,057 & 0,130 & 0,130 & 0,622 \\
Crt 6 & 0,081 & 0,045 & 0,017 & 0,022 & 0,011 & 0,130 & 0,130 & 0,352 \\
Crt 7 & 0,081 & 0,045 & 0,017 & 0,022 & 0,019 & 0,043 & 0,043 & 0,243 \\
Jumlah & 1 & 1 & 1 & 1 & 1 & 1 & 1 & 7 \\
\hline
\end{tabular}

Tabel 4. Prioritas dan Ranking Pada Kriteria

\begin{tabular}{cccc}
\hline Kriteria & Prioritas & $\begin{array}{c}\text { Persentase } \\
\text { Prioritas }\end{array}$ & Rangking Prioritas \\
\hline Kriteria1 & 0,331 & 33,1 & 1 \\
Kriteria 2 & 0,202 & 20,2 & 2 \\
Kriteria 3 & 0,179 & 17,9 & 3 \\
Kriteria 4 & 0,114 & 11,4 & 4 \\
Kriteria 5 & 0,089 & 8,9 & 5 \\
Kriteria 6 & 0,050 & 5,0 & 6 \\
Kriteria 7 & 0,035 & 3,5 & 7 \\
Jumlah & 7 & & \\
\hline
\end{tabular}

Perhitungan nilai kriteria prioritas pada tabel 4 adalah :

$\mathrm{C} 1=2,319 / 7=0,331$
$\mathrm{C} 2=1,412 / 7=0,202$
$\mathrm{C} 3=1,256 / 7=0,179$
$\mathrm{C} 4=0,796 / 7=0,114$
$\mathrm{C} 5=0,622 / 7=0,089$
$\mathrm{C} 6=0,352 / 7=0,050$
$\mathrm{C} 7=0,243 / 7=0,035$

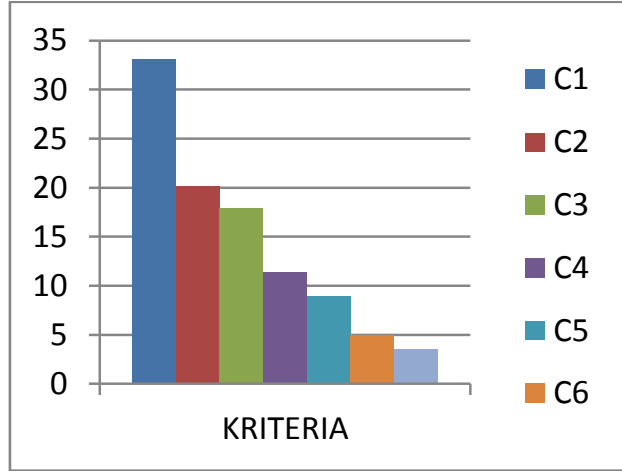

Gambar 2. Persentase Kriteria Prioritas dalam Diagram Batang

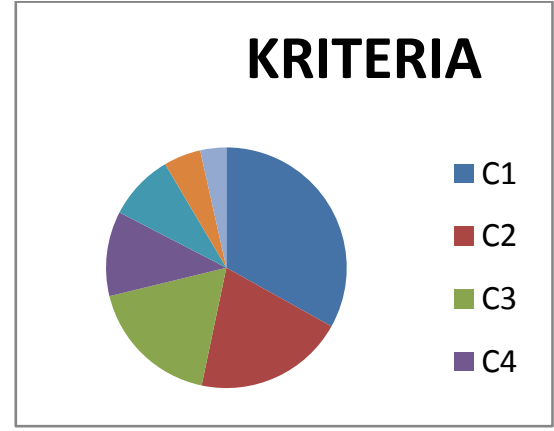

Gambar 3. Persentase Alternatif Prioritas Dalam Diagram Pie

Penilaian indeks konsistensi pada kriteria perhitungan menjadi konsistensi jika angka rasio konsistensi hierarkis (CR) $<0,1$

$$
C R=\frac{C I}{R I}
$$

dimana CR = Ratio of Consistency

$\mathrm{CI}=$ Index of Consistency

$\mathrm{RI}=$ Random Index

$$
\mathrm{CI}=\frac{[\lambda \max -n]}{\mathrm{n}-1}
$$


di mana $\mathrm{n}=$ banyak elemen

$\lambda$ maks $=$ angka eigen

Nilai maksimum dari jumlah perkalian dalam kolom matriks synthes sebanding pada kriteria di tabel 2 juga tabel 4 . Nilai eigen maks adalah: $\lambda$ maks $=7,676$

$$
C I=\frac{7,676}{(7-1)} \quad \mathrm{CI}=0,11260153
$$

Penentuan angka $\mathrm{RI}=1,32$ dari tabel dengan nilai $\mathrm{n}=7$.

$$
C R=\frac{0,11269153}{1,32}=0,085304189
$$

Hasil $C R=0,085304189$ terpenuhi syarat, $\mathrm{CR}<0,1$ pemilihan model pembelajaran dinyatakan konsisten/benar. Pada perbandingan matriks alternatif sesuia kriteria yang terpilih yaitu Tujuan Pembelajaran (Crt1). Alternatif (Alt) pemilihan model pembelajaran adalah: Pendekatan Pembelajaran (Alt1), Strategi Pembelajaran (Alt2), Metode Pembelajaran (Alt3) dan Teknik dan Taktik Pembelajaran (Alt4).

Perhitungan nilai alternatif prioritas pada tabel 8 adalah :

$$
\begin{aligned}
& \text { Alt } 1=0,589 / 4=0,147 \\
& \text { Alt2 }=0,889 / 4=0,222 \\
& \text { Alt3 }=2,214 / 4=0,554 \\
& \text { Alt4 }=0,308 / 4=0,077
\end{aligned}
$$

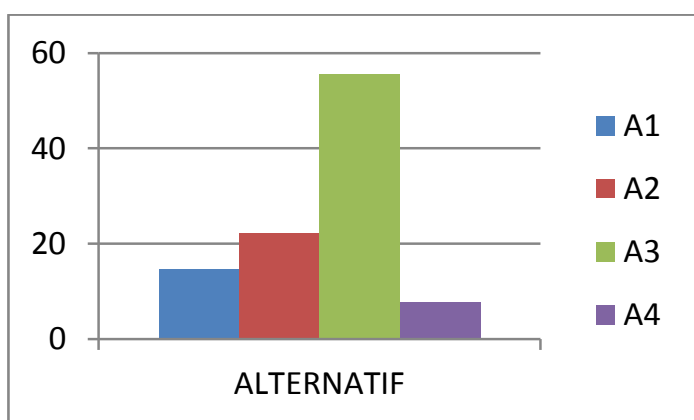

Gambar 5. Persentase Alternatif

Prioritas dalam Diagram Batang

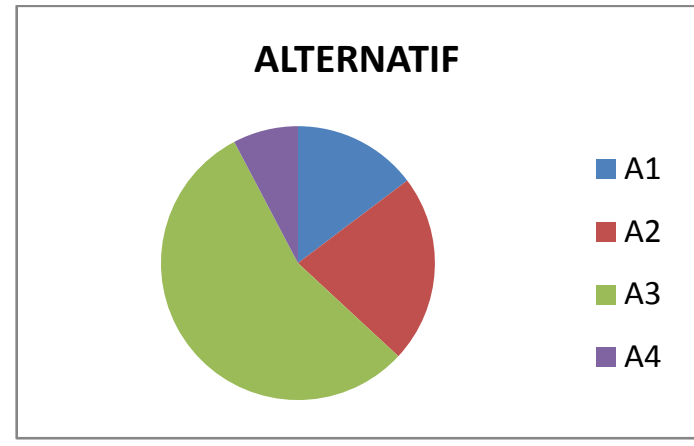

Gambar 6. Persentase Alternatif Prioritas Dalam Diagram Pie

Penilaian indeks konsistensi pada alternatif adalah :

$$
\begin{aligned}
& \lambda \text { maks }=(8,333 * 0,147)+(4,833 * 0,222) \\
& +(41,733 * 0,554)+(12 \\
& * 0,077) \\
& \lambda \text { maks }=4,184 \\
& C I=\frac{4,184-4}{(4-1)} \\
& \mathrm{CI}=0,06125393
\end{aligned}
$$

Penentuan angka RI $=0,9$ dari tabel dengan nilai $\mathrm{n}=4$.

$$
C R=\frac{0,06125393}{0,9}
$$

$\mathrm{CR}=0,068059922$, bersifat konsisten dimana $\mathrm{CR}<0,1$.

Tujuan Pembelajaran (Crt1) adalah alternatif ketiga (Alt3) yaitu Metode Pembelajaran yang dipilih sesuai dengan kriteria yang dipilih.

Tabel 5. Random Index

\begin{tabular}{ccccccccccccccc}
\hline $\mathrm{n}$ & 1,2 & 3 & 4 & 5 & 6 & 7 & 8 & 9 & 10 & 11 & 12 & 13 & 14 & 15 \\
\hline $\mathrm{RI}$ & 0 & 0,58 & 0,90 & 1,12 & 1,24 & 1,32 & 1,41 & 1,45 & 1,49 & 1,51 & 1,48 & 1,56 & 1,57 & 1,59 \\
\hline
\end{tabular}


DOI: https://doi.org/10.33330/jurteksi.v7i3.1155

Available online at http://jurnal.stmikroyal.ac.id/index.php/jurteksi

Tabel 6. Perhitungan Pada Alternatif

\begin{tabular}{ccccc}
\hline Alt (A) & Alt1 & Alt2 & Alt3 & Alt4 \\
\hline Alt 1(A1) & 1 & 0,5 & 0,2 & 3 \\
Alt 2(A2) & 2 & 1 & 0,33 & 3 \\
Alt 3(A3) & 5 & 3 & 1 & 5 \\
Alt 4(A4) & 0,333 & 0,333 & 0,2 & 1 \\
Jumlah & 8,333 & 4,833 & 1,733 & 12 \\
\hline
\end{tabular}

Tabel 7. Normalisasi Pada Alternatif

\begin{tabular}{cccccc}
\hline Alt(A) & Alt1 & Alt2 & Alt3 & Alt4 & Jumlah \\
\hline Alt 1 & 0,120 & 0,103 & 0,115 & 0,250 & 0,589 \\
Alt 2 & 0,240 & 0,207 & 0,192 & 0,250 & 0,889 \\
Alt 3 & 0,600 & 0,621 & 0,577 & 0,417 & 2,214 \\
Alt 4 & 0,040 & 0,069 & 0,115 & 0,083 & 0,308 \\
Jumlah & 1 & 1 & 1 & 1 & 4 \\
\hline
\end{tabular}

Tabel 8. Prioritas dan Ranking Pada Alternatif

\begin{tabular}{cccc}
\hline Alternatif & $\begin{array}{c}\text { Nilai } \\
\text { Prioritas }\end{array}$ & $\begin{array}{c}\text { Priorotas } \\
\text { (Persentase) }\end{array}$ & Rangking \\
\hline Alternatif 1 & 0,147 & 14,7 & 3 \\
Alternatif 2 & 0,222 & 22,2 & 2 \\
Alternatif3 & 0,554 & 55,4 & 1 \\
Alternatif 4 & 0,077 & 7,7 & 4 \\
Jumlah & 1 & 100 & \\
\hline
\end{tabular}

Tabel 9. Tabel Hasil Perhitungan Secara AHP pada Pemeringkatan Kriteria

\begin{tabular}{ccc}
\hline Kriteria & Deskripsi & Rangking \\
\hline Crt1 & Tujuan Pembelajaran & 1 \\
Crt2 & Kemampuan Dosen & 2 \\
Crt3 & Kemampuan Mahasiswa & 3 \\
Crt4 & Jumlah Mahasiswa & 4 \\
Crt5 & Jenis Materi & 5 \\
Crt6 & Waktu & 6 \\
Crt7 & Fasilitas yang Tersedia & 7 \\
\hline
\end{tabular}

Tabel 10. Tabel Hasil Perhitungan Secara AHP pada Pemeringkatan Alternatif

\begin{tabular}{ccc}
\hline Alternatif & Deskripsi & Rangking \\
\hline Alt3 & Metode Pembelajaran & 1 \\
Alt2 & Strategi Pembelajaran & 2 \\
Alt1 & Pendekatan Pembelajaran & 3 \\
Alt4 & Teknik dan Taktik Pembelajaran & 4 \\
\hline
\end{tabular}

\section{SIMPULAN}

Penggunaan metode AHP mampu menghasilkan pemilihan pengembangan model pembelajaran dengan beberapa kriteria pemilihan yang berpengaruh dan juga alternatif-alternatif terpilih. Nilai rangking yang diperoleh dengan nilai tertinggi adalah solusi yang terpilih pada kriteria dan alternatif pada pemilihan model pembelajaran di STMIK Royal Kisaran 


\section{DAFTAR PUSTAKA}

[1] W. Wasis and M. Ibrahim, "PENGEMBANGAN

PERANGKAT

PEMBELAJARAN

BERDASARKAN MASALAH BERBASIS EDUTAINMENT UNTUK MELATIHKAN KREATIVITAS SISWA SMK JURUSAN OTOMOTIF PADA MATERI FLUIDA STATIS," JPPS (Jurnal Penelit. Pendidik. Sains), 2017, doi: 10.26740/jpps.v7n1.p1431-1440.

[2] A. S. Wulandari, I. N. Suardana, and N. L. P. L. Devi, "PENGARUH MODEL PEMBELAJARAN BERBASIS PROYEK TERHADAP KREATIVITAS SISWA SMP PADA PEMBELAJARAN IPA,"

J. Pendidik. dan Pembelajaran Sains Indones., 2019, doi: 10.23887/jppsi.v2i1.17222.

[3] sufairoh, "Pendekatan Saintifik dan Model Pembelajaran," Bahastra, 2016.

[4] Z. Azhar and M. Handayani, "ANALISIS FAKTOR PRIORITAS DALAM PEMILIHAN PERUMAHAN KPR MENGGUNAKAN METODE AHP," J. Manaj. Inform. dan Sist. Inf., 2018, doi: 10.36595/misi.v1i2.38.

[5] Z. Azhar, "Analisis Faktor Prioritas dalam Pemilihan Mata Kuliah Praktek pada Prodi Sistem Informasi Menggunakan Metode AHP," Digit. Zo. J. Teknol. Inf. dan Komun., 2020, doi: 10.31849/digitalzone.v11i1.3393.

[6] Z. Azhar, "Faktor Analisis Prioritas Dalam Pemilihan Bibit Jagung Unggul Menggunakan
Metode AHP," Semin. Nas Teknol. Komput. Sains ..., 2020.

[7] R. A. Suherdi, R. Taufiq, and A. A. Permana, "Penerapan Metode AHP dalam Sistem Pendukung Keputusan Kenaikan Pangkat Pegawai Di Badan Kepegawaian Dan Pengembagan Sumber Daya Manusia Kota Tangerang," Sintak, 2018.

[8] S. Indra, Adi and T. Rohmat, "Penerapan Metode Analytical Heirarchy Process (Ahp) Dalam Sistem Pendukung Keputusan (Spk) Pemensiunan Pada Badan Kepegawaian Dan Pengembangan Sumber Daya Manusia Kota Tangerang," Pros. SINTAK 2018, 2018.

[9] R. Umar, A. Fadlil, and Y. Yuminah, "Sistem Pendukung Keputusan dengan Metode AHP untuk Penilaian Kompetensi Soft Skill Karyawan," Khazanah Inform. J. Ilmu Komput. dan Inform., 2018, doi: 10.23917/khif.v4i1.5978.

[10] A. Fauzi and T. Hidayatulloh, "Penilaian Kinerja Karyawan Pada PT. Telecom Visitama Menggunakan Metode Analytical Hierarchy Process," Indones. J. Comput. Inf. Technol., 2017.

[11] D. Desyanti, "SISTEM PENDUKUNG KEPUTUSAN PEMILIHAN KARYAWAN TELADAN MENGGUNAKAN METODE ANALITICY HIERARCY PROCESS (AHP)," INOVTEK Polbeng - Seri Inform., 2016, doi: 10.35314/isi.v1i1.127.

[12] Z. Azhar, "PENERAPAN METODE ANALYTICAL HIERARCHY PROCESS DALAM PEMILIHAN BIBIT JAGUNG UNGGUL," JURTEKSI 
(Jurnal Teknol. dan Sist. Informasi), 2020, doi: 10.33330/jurteksi.v6i2.528.

[13] Z. Azhar and J. Hutahaean, "Penerapan Metode Analytical Hierarchy Process Dalam Pemilihan Tempat Cafe di Kisaran," Build. Informatics, Technol. Sci., 2020, doi: 10.47065/bits.v2i2.560.

[14] G. Istiningsih, E. M. L.A, and E. Prihalina, "Pengembangan Model Pembelajaran 'Promister' untuk Meningkatkan Hasil Belajar Wayang Pandhawa Pada Siswa Sekolah Dasar," J. Holistika, 2018.

[15] N. I. Cintia, F. Kristin, and I. Anugraheni, "PENERAPAN MODEL PEMBELAJARAN DISCOVERY LEARNING UNTUK MENINGKATKAN KEMAMPUAN BERPIKIR KREATIF DAN HASIL BELAJAR SISWA," Perspekt. Ilmu Pendidik., 2018, doi: 10.21009/pip.321.8.

[16] A. Asyafah, "MENIMBANG MODEL PEMBELAJARAN," TARBAWY Indones. J. Islam. Educ., 2019, doi: 10.17509/t.v6i1.19459.

[17] N. R. Mitasari, "MODEL PEMBELAJARAN

EDUTANIMENT TERHADAP PERKEMBANGAN KOGNITIF SISWA SEKOLAH DASAR," $J$. Cakrawala Pendas, 2018, doi: 10.31949/jcp.v4i1.698.

[18] T. Pangajuanto, "Peningkatan Kompetensi Menimbang Dengan Neraca Analitis Melalui Model Pembelajaran Team Assisted Individualization (Tai) Pada Siswa Kelas X Ki A Smk Negeri 2 Sukoharjo Semester 1 Tahun
Pelajaran 2019/2020," Inkuiri J.

Pendidik. IPA, 2020, doi: 10.20961/inkuiri.v9i1.41409.

[19] A. Jayul and E. Irwanto, "Model Pembelajaran Daring Sebagai Alternatif Proses Kegiatan Belajar Pendidikan Jasmani di Tengah Pandemi Covid-19 Achmad," J. Pendidik. Kesehat. Rekreasi, 2020.

[20] D. Andayati, "Sistem Pendukung Keputusan Pra-Seleksi Penerimaan Siswa Baru (Psb) onLine Yogyakarta," J. Teknol., 2010

[21] W. R. Susila and E. Munadi, "Penggunaan Analytical Hierarchy Process Untuk Penyususunan Prioritas Proposal Penelitian," Inform. Pertan., 2007.

[22] A. A. Khairun Nisa, S. Subiyanto, and S. Sukamta, "Penggunaan Analytical Hierarchy Process (AHP) Untuk Pemilihan Supplier Bahan Baku," J. Sist. Inf. BISNIS, 2019, doi: 10.21456/vol9iss1pp86-93.

[23] R. D. F. S. M. Russo and R. Camanho, "Criteria in AHP: A systematic review of literature," in Procedia Computer Science, 2015, doi: 10.1016/j.procs.2015.07.081.

[24] A. A. Longaray, J. De Deus Rodrigues Gois, and P. R. Da Silva Munhoz, "Proposal for using AHP method to evaluate the quality of services provided by outsourced companies," in Procedia Computer Science, 2015, doi: 10.1016/j.procs.2015.07.083.

[25] Y. Han, Z. Wang, X. Lu, and B. $\mathrm{Hu}$, "Application of AHP to road selection," ISPRS Int. J. Geo- 
DOI: https://doi.org/10.33330/jurteksi.v7i3.1155

Available online at http://jurnal.stmikroyal.ac.id/index.php/jurteksi

Information, 2020, doi: 10.3390/ijgi9020086.

[26] A. Altamirano-Corro and R. Peniche-Vera, "Measuring the institutional efficiency using dea and ahp: The case of a mexican university," J. Appl. Res. Technol., 2014, doi: 10.1016/S1665-6423(14)71606-2.

[27] N. Sael, T. Hamim, and F. Benabbou, "Implementation of the Analytic Hierarchy Process for student profile analysis," Int. J. Emerg. Technol. Learn., 2019, doi: 10.3991/ijet.v14i15.10779.

[28] A. Munthafa and H. Mubarok,
"Penerapan Metode Analytical Hierarchy Process Dalam Sistem Pendukung Keputusan Penentuan Mahasiswa Berprestasi," J. Siliwangi, 2017.

[29] Z. Azhar, "Analisis Pemilihan Mata Kuliah Praktek Menggunakan Metode AHP," Pros. Semin. Nas. Ris. Inf. Sci., 2019 , doi: 10.30645/senaris.v1i0.126. 